Editorial

\section{Peter J Janetta MD, DSci. FAANS}

(April 5, 1932-April 11, 2016)

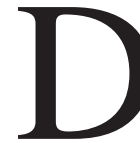
$r$ Janetta was a pioneer in Micro vascular decompression (MVD). His contribution to neurosurgery for devising the Janetta procedure or micro vascular decompression of cranial nerves is immense and highly commendable.

He completed his neurosurgical residency from UCLA in 1966. Jannetta began researching the causes of chronic facial pain during a residency at the University of California at Los Angeles. After finishing his residency, Jannetta became associate professor and chief of neurosurgery at the Louisiana State University School of Medicine in New Orleans.

He became chairman of the newly formed Department of Neurological Surgery at the University of Pittsburgh in 1971 and served in that role for more than 25 years. After leaving the university, Dr. Jannetta helped develop the Cranial Nerve Center at Allegheny General Hospital in Pittsburgh.

He performed his first MVD in 1966 for hemifacial spam and 3 months later for Trigeminal Neuralgia. His seminal contributions to the understanding and treatment of Neuro-vascular compression syndromes of the brainstem and cranial nerves are internationally known. He has more than 400 scientific articles, abstracts and book chapters.

Apart from being a Neurosurgeon, he used to play Banjo and was an avid art enthusiast. He has donated about 130 pieces of art to museums.

He established the Jannetta Neuroscience Foundation for research and educated patients on the cranial nerve compression. He is survived by his wife and 6 children, two of whom are surgeons. As a teaching surgeon, he has mentored

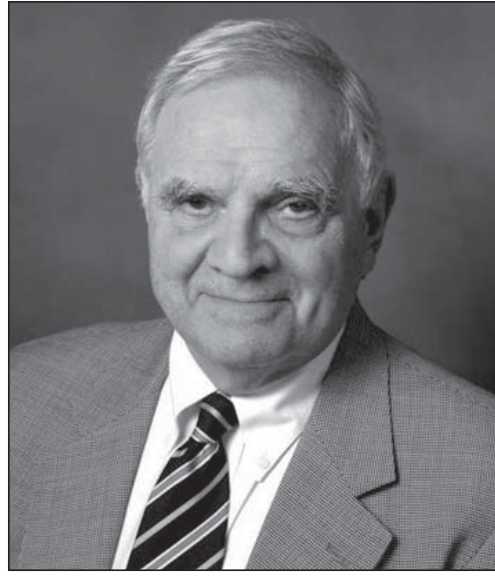

some 150 neurosurgeons, many of whom have become chairmen of their departments in the United States and other countries.

\section{Affiliations, awards and honors}

- 1983, received the Herbert Olivecrona Award from Karolinska Institute, Sweden

- 1990, selected as Vectors/Pittsburgh Man of the Year in the Sciences

- 1991-92, Vice president of Society of Neurological Surgeons

- Walter E. Dandy Professor of Neurosurgery at the University of Pittsburgh School of Medicine. (The University later in 1992 established a chair in his name).

- 2000, received the Fedor-Krause Medal of Honor, by the German Neurosurgical Society

- 2006, awarded Zulch Prize for Medical Research from the Max Planck Society for the Advancement of Science

- 2008, received Distinguished Citizen of the Commonwealth Award from the Pennsylvania Society

- 2009, received World Federation of Neurosurgical Societies (WFNS)' Distinguished Medal of Honor

Our heartfelt tribute and respect to both of the above scholars for their commendable job in the field of not only neurosurgery, but also the whole medical science.

May their souls reside in eternal peace. 